January 2015

\title{
HIV prevalence in blood donors and recipients in Pakistan: a meta-analysis and analysis of blood- bank data
}

Bushra Moiz

Aga Khan University, bushra.moiz@aku.edu

Barkat Ali

Aga Khan University

Muhammad Hasnain Chatha

Aga Khan University

Ahmed Raheem

Aga Khan University, ahmed.raheem@aku.edu

Hasan Abbas Zaheer

Follow this and additional works at: https://ecommons.aku.edu/

pakistan_fhs_mc_pathol_microbiol

Part of the Hematology Commons, Microbiology Commons, and the Pathology Commons

\section{Recommended Citation}

Moiz, B., Ali, B., Chatha, M. H., Raheem, A., Zaheer, H. A. (2015). HIV prevalence in blood donors and recipients in Pakistan: a metaanalysis and analysis of blood-bank data. WHO South-East Asia Journal of Public Health, 4(2), 176-183.

Available at: https://ecommons.aku.edu/pakistan_fhs_mc_pathol_microbiol/867 


\title{
HIV prevalence in blood donors and recipients in Pakistan: a meta-analysis and analysis of blood-bank data
}

\author{
Bushra Moiz', Barkat Ali², Muhammad Hasnain Chatha², \\ Ahmed Raheem ${ }^{1}$, Hasan Abbas Zaheer ${ }^{3}$
}

\begin{abstract}
Background: The first instances of HIV-antibody detection in donated blood in Pakistan were reported in 1988. Since then, documentation of HIV in blood donors and of rates of transmission via transfusion has been limited. Previously assumed to have a low prevalence, HIV is an increasing health concern in Pakistan. Since there is no national, centralized blood-banking system, there are no reliable data on which to base estimated risks of transfusion-associated HIV infection. This study was therefore conducted to estimate the prevalence of HIV in blood donors and recipients in Pakistan between 1988 and 2012.
\end{abstract}

Methods: Meta-analyses were undertaken of reported prevalences of HIV in blood donors and recipients published during 1988-2012. Papers were identified by searching PubMed, Google, CINAHL and PakMediNet and the websites of the World Health Organization, the national HIVIAIDS Surveillance Project and the National AIDS Control Programme of Pakistan. In addition, the 1998-2012 records of the Aga Khan University blood bank were analysed.

Results: The 254 abstracts identified at the preliminary search were reviewed and, after removal of duplications, case-reports, editorials and reviews, 32 papers were selected that met the inclusion criteria. All studies that reported on HIV antibodies in blood donors/recipients were included, irrespective of the methodology used. Since seroconversion had only been confirmed through supplemental testing in a few papers, the results were analysed separately for reports based on screening only and confirmed cases. A total of 142 of 2023379 blood donors and 4 of 3632 blood recipients were HIV positive, giving an overall pooled seroprevalence of $0.00111 \%$ in blood donors and $0.00325 \%$ in blood recipients. The annual prevalences of HIV in donors at the Aga Khan University blood banks were similar, ranging from $0.013 \%$ to $0.116 \%$.

Conclusion: Very few reports on HIV in blood donors in Pakistan could be retrieved, and the overall pooled prevalence is low. However, the limited data and confounding factors mean that that these results may significantly underestimate the true situation. It is recommended that a complete survey of blood banks should be conducted throughout the country, in order to provide a more reliable estimate of the risk of transfusion-associated HIV infection in Pakistan.

Key words: blood bank, blood donors, blood transfusion, HIV, Pakistan, transfusion-transmitted infection

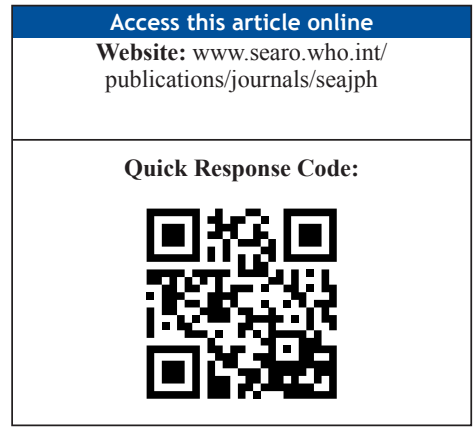

${ }^{1}$ Department of Pathology and Laboratory Medicine, The Aga Khan University Hospital, Karachi, Pakistan, ${ }^{2}$ Aga Khan Medical College, Karachi, Pakistan, ${ }^{3} \mathrm{Safe}$ Blood Transfusion Services Programme, Islamabad, Pakistan, Government of Pakistan
Address for correspondence: Dr Bushra Moiz, Associate Professor and Consultant Haematologist, Department of Pathology and Laboratory Medicine, The Aga Khan University Hospital, Karachi, Pakistan
Email: bushra.moiz@aku.edu

\section{BACKGROUND}

Situated in South Asia, Pakistan is home to 180 million people, with a $54.7 \%$ literacy rate and $61.7 \%$ of its people residing in rural towns. ${ }^{1}$ Though there are 1830 blood providers in the public and private sectors and nongovernmental organizations (NGOs), ${ }^{2}$ the total number of units of blood collected in the entire country is not known exactly. According to an update in 2009 from the Pakistan Society of Haematology, approximately 3 million units are collected in various thalassaemia centres. ${ }^{3}$ 
In 2000, Luby et al. estimated that blood collection in Karachi is done primarily on a transfusion-exchange (75\%) or a paid basis $(25 \%){ }^{4}$ Some of the challenges to the transfusion services include lack of a national blood policy, inadequate recruitment and donor selection, ${ }^{5}$ and the cost of screening kits, coupled with periodic lack of availability of reagents. ${ }^{6,7}$

The Government of Pakistan has taken several initiatives to reform blood-safety systems in the country. In 1986-1987, the National AIDS Control Programme (NACP) was initiated, with a focus on HIV diagnosis in hospitalized patients suspected of being infected with HIV, but later shifted its scope towards HIV prevention, which included mitigation against transfusion-transmitted HIV. NACP was financed by the World Health Organization (WHO) and other donors initially, until the formation of the Joint United Nations Programme on HIV/AIDS (UNAIDS) in $1996 .{ }^{8}$ An important step was promulgation of the Safe Blood Transfusion Act by provincial legislature in 1997, under which the Sindh Blood Transfusion Authority (SBTA) was formed. ${ }^{9}$ SBTA enrolled 146 banks in the province of Sindh that met its standards, and closed down 126 substandard blood banks. ${ }^{10}$ Similar initiatives were subsequently taken by other provinces. More recently, the government officially consolidated its blood-safety initiatives, by establishing a National Blood Transfusion Project (NBTP) in March 2009. With NBTB established at the national and provincial levels, the foundation has now been laid for a system that will ensure adequate and nationwide access to a safe, adequate and affordable blood supply. ${ }^{11}$ The German Federal Ministry for Economic Cooperation and Development is providing technical and financial support for this initiative.

In a recent meta-analysis, the national prevalence of hepatitis $\mathrm{C}$ and $\mathrm{B}$ virus in blood donors in Pakistan was estimated to be $2.8 \%$ and $2.3 \%$ respectively. ${ }^{12}$ However, there is a paucity of data on the prevalence of HIV in blood donors and rates of transfusion-transmitted HIV. For example, it is not known whether the seroprevalence of HIV is static or increasing in Pakistani blood donors. Initial reports of transfusion-associated HIV were published in 1988 by Mujeeb and $\mathrm{Hashmi}^{13}$ and Khanani et al. ${ }^{14}$ For 2013, the estimated adult prevalence of HIV in Pakistan was $0.07 \%$ and there were an estimated 2200 HIV-related deaths. ${ }^{1}$ In 2009, UNAIDS Pakistan and NACP estimated that there were 98000 (range $79000-120000$ ) HIV cases in Pakistan, with an overall HIV prevalence of less than $0.05 \%$; and that seroprevalence among injecting drug users (an estimated prevalence of 20\%) and their sexual contacts, including male and transgender hijra sex workers, was increasing. ${ }^{8}$

Since documentation of transfusion transmission of HIV has been limited, this study aimed to estimate the prevalence of HIV in blood donors and recipients during 1988-2012, through meta-analysis of published data. In addition, data from the Aga Khan University blood bank records for 1998-2012 were analysed.

\section{METHODS}

\section{Search strategy}

The MOOSE (Meta-analysis Of Observational Studies in Epidemiology) group checklist for reporting meta-analysis of observational studies was used..$^{15}$ Two authors conducted individual searches for papers published in the past 25 years (from January 1988 to December 2012), using all databases available to the institute, i.e. PubMed, Google search, CINAHL and PakMediNet. The latter is a search engine that encompasses the non-indexed locally published literature. The following key words were used: "HIV" AND "blood donors", "blood recipients", "multiply transfused", "thalassaemia", "haemophilia" AND "Pakistan". Additional articles were identified by searching for specific authors in this field and through the cited references of relevant articles from the Google search engine. WHO, the Pakistan HIV/AIDS Surveillance Project and NACP were also searched, to capture any additional relevant papers. Bibliographies of published full manuscripts were searched for additional manuscripts. Only papers published in English were included, as local medical journals are published in this language.

\section{Inclusion and exclusion criteria}

The preliminary search yielded 254 abstracts, 190 from PubMed, 21 from CINAHL and 43 from PakMediNet. After removing duplications, two experts independently selected 38 abstracts that were relevant. Case-reports, editorials and reviews $(n=6)$ were excluded from further analysis; 32 papers met the inclusion criteria for review. All studies that reported on HIV antibodies in blood donors/recipients were included, irrespective of the methodology used. Since only a few papers reported that seroconversion had been confirmed through supplemental testing, the results were analysed separately for reports based on screening only and confirmed cases.

\section{Data handling and statistical analysis}

Data regarding the time period of the study, region (province), population of study (donor or recipient), total sample size, percentages and numbers of positive cases, and methodology were extracted from the articles. If the same study included both donors and recipients or had been done in more than one location, it was split and the results were indicated separately according to the group. Where results were mentioned in percentages, the absolute values were calculated from the population denominator. STATA 12 was used to analyse the data for the pooled prevalence. All meta-analyses were evaluated for heterogeneity, using the $\chi^{2}$-based $I^{2}$ test. $I^{2}$ values were interpreted as: $0 \%, 25 \%, 50 \%$ and $75 \%$, to indicate no heterogeneity, low-level, moderate-level or high-level heterogeneity, respectively. For moderate-level or high-level heterogeneity, a random-effects meta-analysis was performed. Forest plots for unadjusted prevalence estimates with $95 \%$ confidence limits were generated. ${ }^{16}$ A $P$ value of $<0.05$ was considered significant. 


\section{Aga Khan University blood bank data, 1998-2012}

Blood-bank donor data from the records of the Aga Khan University were also analysed. Data from all blood donors enrolled and tested for HIV between 1998 and 2012 were included. The methodology was enzyme-linked immunosprbent assay (ELISA; Axysm and ARCHITECT ci1000, Abbott Diagnostic Division, Abbott Park, IL, United States of America) until 2009 and chemiluminescence (Vitros ${ }^{\odot}$, Ortho Clinical Diagnostics, Johnson \& Johnson, Raritan, NY, United States of America) in later years. From July 2011, reactive samples were retested on another instrument (Cobas ${ }^{\circledR}$ 601e analyser, Roche Diagnostics $\mathrm{GmbH}$, Mannheim, Germany). Repeatedly reactive samples were further confirmed through western blot.

\section{RESULTS}

The full texts of 32 published papers were eligible for analysis. Twenty-five manuscripts related to HIV prevalence in blood donors were found, ${ }^{17-41}$ six that described HIV risk in both donors and recipients, ${ }^{13,14,42-45}$ and only one study that was dedicated exclusively to HIV seroprevalence in transfusion recipients. ${ }^{46}$

\section{HIV seroprevalence and methodology used in blood donors}

Thirty-one studies were evaluated to describe the prevalence of HIV in blood donors in Pakistan. ${ }^{13,14,17-45}$ The overall pooled seroprevalence of HIV in blood donors was $0.00111 \%$ $(95 \%$ confidence interval $[\mathrm{CI}]=-0.00044 \%$ to $0.00267 \%)$, $I^{2}=89.7 \%, P<0.00001$ ) (see Fig. 1). The data were from nine large cities of the country and 10 studies were conducted in the city of Karachi alone, ${ }^{13,14,17-20,38,40,42,45}$ while six and four were conducted in Lahore $25,28,30,36,37,44$ and Peshawar, $22,39,41,43$ respectively. ELISA was the predominant screening technology used in 27 studies, ${ }^{13,14,17-20,22,23,25,29,32-41,42,45}$ one paper did not describe the methodology used, ${ }^{31}$ while the remaining three studies were based exclusively either on immunochromatographic testing ${ }^{24,30}$ or latex agglutination. ${ }^{21}$ During 1988-2012, a total of 142 donors were reported to have HIV antibodies. Of these, 128 of $652019(0.02 \%)$ tests were based on ELISA, while in four reports, 14 of $1350205(0.001 \%)$ tests were confirmed with supplemental testing. ${ }^{14,18,25,40}$ There was no HIV recorded in 18 of the studies. ${ }^{13,17,19-21,24,27,29-32,34,38,41,42-45}$ A total of 11 public-sector blood banks associated with various teaching hospitals yielded 27 reports, with a total of 1875532 tested donors identifying 125 subjects $(0.0067 \%)$ with HIV antibodies. In contrast, only three studies were conducted at two private hospital blood banks linked to academic institutes. ${ }^{18,40,45}$ They reported HIV in two of 89101 blood donors $(0.002 \%)$ who were screened. Four papers described HIV seroconversion in 14 of the 52625 blood donors $(0.03 \%)$ enrolled in four NGOs, ${ }^{24,35,36,41}$ while one report was the combined effort of an NGO with a teaching hospital. ${ }^{27}$ One study did not mention the names of the blood banks that took part in the study; ${ }^{14}$ this was a small study with 121 donors, reporting HIV in one donor.

\section{Donor sex and HIV}

A total of 17 of the 31 studies on blood donors did not did not report the sex of the participants. Fourteen reports described 285208 sex-wise donations, including 258628 male $(90.7 \%)$ and 26580 female $(9.3 \%)$ donors. ${ }^{18-21,23,27,28,30-32,37,38,42,45}$ However, except for one study, ${ }^{18}$ the HIV results were not delineated with respect to sex.

\section{Donor type and HIV}

Donor types were described in 15 reports only. Khanani et al. $(n=121)$ reported the results exclusively in $121 \mathrm{paid} /$ professional donors and found a single $(0.8 \%)$ HIV-reactive donation. ${ }^{14}$ Similarly, Mujeeb and Mehmood described the HIV risk in 839 family/replacement or exchange-transfusion donors and the incidence was reported as nil. ${ }^{19}$ Six reports described the HIV risk solely in unpaid voluntary donors, ${ }^{20,27,28,30,36,44}$ and the result was reported as zero in four reports, ${ }^{20,27,30,44}$ and $0.2 \%$ and $0.045 \%$ in two other studies. ${ }^{28,36}$ However, the latter studies were ELISA based and their results were not confirmed through supplemental testing. Four papers described the HIV seroprevalence in combined unpaid voluntary or family/ replacement donors, ${ }^{23,26,33,37}$ and the HIV reactivity ranged from $0.004 \%$ to $0.23 \%$. The HIV prevalence in paid and unpaid donors from slum areas of Karachi was reported in three reports, ${ }^{13,17,42}$ but it was reported as nil.

\section{Trend of HIV in blood donors}

The data did not show any rising or declining trend of HIV over a period of 25 years from 1988 when initial cases of HIV in blood donations were reported. ${ }^{13,14}$ A frequency of $<0.3 \%$ was maintained through the study period, from various places of the country, irrespective of the donor type and the category of blood bank.

\section{HIV seroprevalence in blood donors at Aga Khan University blood bank}

From 1998 to 2012, 306316 blood donors were enrolled and tested for HIV at the Aga Khan University blood bank; of these, $95.5 \%$ were male and $87 \%$ were family/replacement donors. Table 1 summarizes the overall, donor-type and sex-wise details for HIV seroprevalence. There were 167 donors who tested positive for HIV. Results of western blot on a total of 16 samples were as follows: positive $(n=5$ or $31 \%)$, indeterminate $(n=6$ or $38 \%)$ and negative $(n=5$ or $31 \%)$. Donors with indeterminate results were not followed up. Also, overall, in male and family/exchange donors, the seroprevalence of HIV was low, ranging from $0.013 \%$ to $0.116 \%$. Seroprevalence was not computed for female and voluntary donors because of small denominators. 


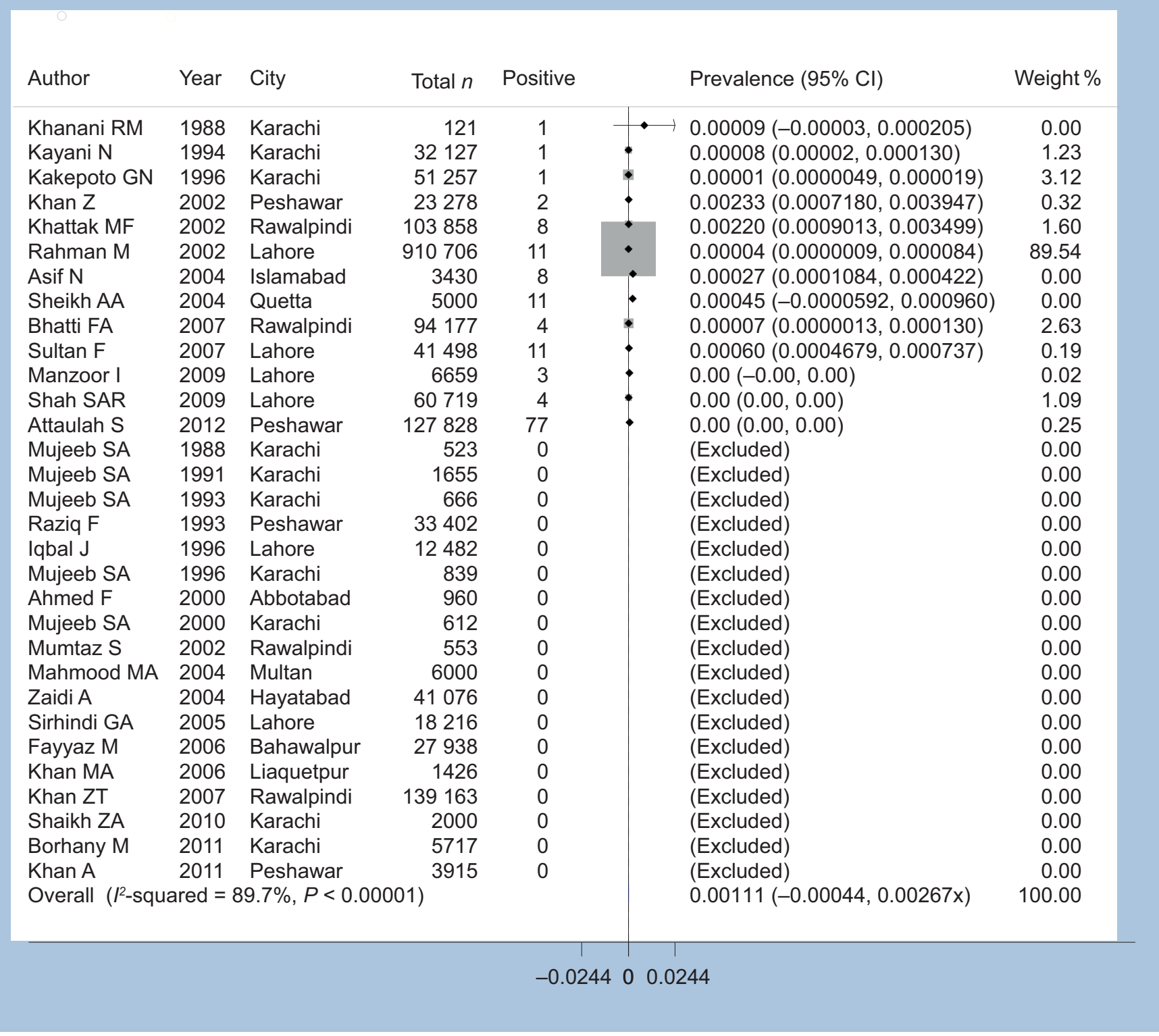

Figure 1: Prevalence of HIV positivity in blood donors in Pakistan

Forest plot showing prevalence (\%) estimates (black solid diamonds) with 95\% confidence intervals (bars). Shaded boxes denote the weight allocated to each study based on sample size. The overall pooled prevalence estimate $0.00111 \%(95 \%$ confidence interval $[\mathrm{Cl}]=-0.00044 \%$ to 0.00267 ) was too low to be plotted on the graph.

\section{HIV in transfusion recipients}

Seven studies described the prevalence of HIV in multiply transfusedbloodrecipients, includingthosewithhaemophilia, ${ }^{14,45}$ and polytransfused ${ }^{13,14,42-44,46}$ and haemodialysed $\mathrm{d}^{42,44}$ patients. Except for one study ${ }^{45}$ HIV results were confirmed through supplemental testing (western blot or p24 antigen). The pooled data indicated that only 3632 transfusion recipients were studied and only four were reactive for HIV, with an overall prevalence of $0.00325 \%$ (95\% CI $=-0.00135$ to 0.00648 ; see Fig. 2). However, there are too few data to draw any meaningful conclusions regarding the prevalence of HIV in blood recipients. All HIV-reactive patients had received multiple transfusions; 888 of them had had transfusions with unscreened blood products, ${ }^{13}$ and two were reported to have acquired HIV through blood transfusions. ${ }^{13}$ 


\begin{tabular}{|c|c|c|c|c|c|c|}
\hline Year & Donors, $n$ & Males, $n(\%)$ & $\begin{array}{c}\text { Family/ } \\
\text { replacement } \\
\text { donors, } n(\%)\end{array}$ & $\begin{array}{l}\% \text { HIV prevalence } \\
(95 \% \mathrm{Cl}) \text { in donors }\end{array}$ & $\begin{array}{l}\text { \% HIV prevalence } \\
(95 \% \text { Cl) in male } \\
\text { donors }\end{array}$ & $\begin{array}{c}\% \text { HIV prevalence in } \\
\text { family/replacement } \\
\text { donors }\end{array}$ \\
\hline 1998 & 15070 & $14317(95)$ & $11235(75)$ & $0.013(0.011$ to 0.015$)$ & $0.014(0.012$ to 0.014$)$ & $0.018(0.015$ to 0.020$)$ \\
\hline 1999 & 12300 & $11685(95)$ & $8636(70)$ & 0.024 (0.022 to 0.027$)$ & 0.026 (0.023 to 0.026$)$ & 0.035 (0.031 to 0.039$)$ \\
\hline 2000 & 15194 & $14434(95)$ & $11700(77)$ & 0.007 (0.005 to 0.008$)$ & 0.007 (0.006 to 0.007$)$ & $0.009(0.007$ to 0.010$)$ \\
\hline 2001 & 14992 & $14242(95)$ & $11669(78)$ & $0.013(0.012$ to 0.015$)$ & 0.014 (0.012 to 0.014$)$ & 0.017 (0.015 to 0.019$)$ \\
\hline 2002 & 16333 & $15516(95)$ & $13180(81)$ & $0.012(0.011$ to 0.014$)$ & $0.013(0.011$ to 0.013$)$ & 0.015 (0.013 to 0.017$)$ \\
\hline 2003 & 18384 & $17465(95)$ & $15402(84)$ & 0.065 (0.062 to 0.069$)$ & 0.069 (0.063 to 0.067$)$ & 0.065 (0.061 to 0.069$)$ \\
\hline 2004 & 21849 & $20757(95)$ & $19037(87)$ & 0.064 (0.061 to 0.067$)$ & $0.063(0.062$ to 0.066$)$ & $0.074(0.070$ to 0.077$)$ \\
\hline 2005 & 21411 & $19929(93)$ & $18368(86)$ & 0.051 (0.048 to 0.054$)$ & $0.055(0.050$ to 0.053$)$ & $0.038(0.035$ to 0.041$)$ \\
\hline 2006 & 22924 & $21632(94)$ & $20616(90)$ & 0.074 (0.071 to 0.078$)$ & $0.074(0.073$ to 0.076$)$ & $0.058(0.055$ to 0.061$)$ \\
\hline 2007 & 24994 & $24082(96)$ & $23073(92)$ & $0.120(0.116$ to 0.124$)$ & $0.116(0.112$ to 0.120$)$ & 0.104 (0.100 to 0.108$)$ \\
\hline 2008 & 24191 & $23128(96)$ & $21434(87)$ & $0.037(0.035$ to 0.040$)$ & $0.039(0.036$ to 0.038$)$ & $0.033(0.030$ to 0.035$)$ \\
\hline 2009 & 25427 & $24709(97)$ & $24115(95)$ & 0.071 (0.068 to 0.074$)$ & 0.073 (0.069 to 0.072$)$ & 0.070 (0.067 to 0.074$)$ \\
\hline 2010 & 25116 & $24335(97)$ & $23496(94)$ & 0.044 (0.041 to 0.046$)$ & $0.045(0.043$ to 0.045$)$ & $0.047(0.044$ to 0.050$)$ \\
\hline 2011 & 24572 & $23864(97)$ & $23120(94)$ & 0.094 (0.089 to 0.097$)$ & $0.096(0.092$ to 0.095$)$ & 0.095 (0.091 to 0.099$)$ \\
\hline 2012 & 23559 & $22557(96)$ & 21615 (92) & 0.051 (0.048 to 0.054$)$ & 0.049 (0.046 to 0.052$)$ & 0.051 (0.048 to 0.054$)$ \\
\hline
\end{tabular}

$\mathrm{Cl}$ : confidence interval.

\section{DISCUSSION}

This study showed that the seroprevalence of HIV in blood donors in Pakistan is low at $0.0011 \%$. Although repeatedly transfused patients demonstrated an overall HIV seroprevalence of $0.003 \%$, the number of patients studied was too small to draw any conclusion. With a national prevalence rate of $2-3 \%$ for viral hepatitis $\mathrm{B}$ and $\mathrm{C}$ in blood donors, ${ }^{12} \mathrm{HIV}$ appears to be lowest among the various transfusion-transmitted viral infections. This seems to be even lower than HIV seroprevalence in blood donors reported from neighbouring countries, which is $0.249 \%$ for India, ${ }^{47} 0.004 \%$ for the Islamic Republic of Iran, ${ }^{48}$ and $0.1 \%$ for Nepal. ${ }^{49}$ Overall, the prevalence seems low, but the limited number of studies retrieved from the published literature may mean that the calculated figure does not represent the true prevalence.

The literature search revealed that reports for HIV prevalence in blood donors were available from only 11 public-sector, 4 NGO and 2 private blood banks. This indicates that published reports are not representative of all operational blood banks in the country. In addition, it cannot be assumed that testing is done routinely, since HIV kits are periodically missing in public-sector blood banks. ${ }^{7}$ Since there is no centralized blood banking at national level, it is hard to analyse the situation with confidence. Studies have highlighted the alarming situation in blood banks, whereby prospective donors may be neither screened not interviewed regarding high-risk behaviour., ${ }^{4,9}$
There is currently no insight into the type of blood donation and HIV surveillance in private blood banks and the majority of public blood banks, $20-25 \%$ of which are dependent on paid professional donors. These are potentially injection drug users, among whom the reported HIV prevalence is about $20 \% .^{50}$ One can assume that the reports of low HIV prevalence are far from reality. Other issues observed were the variance in methodology, lack of supplemental testing and small sample size. The poor HIV surveillance and lack of record keeping in banks would not allow for tracking of blood donors. This would result in the same HIV-positive subject donating blood at several places. Individuals reported as replacement donors might include paid donors as well. ${ }^{25}$

In 2000, Luby et al. surveyed 37 randomly selected facilities from a total of 87 in Karachi. ${ }^{4}$ Only 24 agreed to participate. Twelve (50\%) of the facilities reported regularly utilizing paid blood donors, while only six (25\%) actively recruited volunteer donors. Only $8 \%$ of the surveyed facilities ask donors about intravascular drug abuse, and none was prepared to ask about high-risk sexual behaviour. Only 55\% were screening for HIV. It is worth noting that HIV is a taboo subject in the social and religious culture of the country and therefore direct questioning related to HIV is often avoided in the blood banks.

In 2005, 63 blood bank services were visited by field workers under supervision of NACP. A report was prepared by thirdparty evaluation of the quality of HIV screening of blood products. $^{2}$ The report warned that $40 \%$ of observed blood banks 


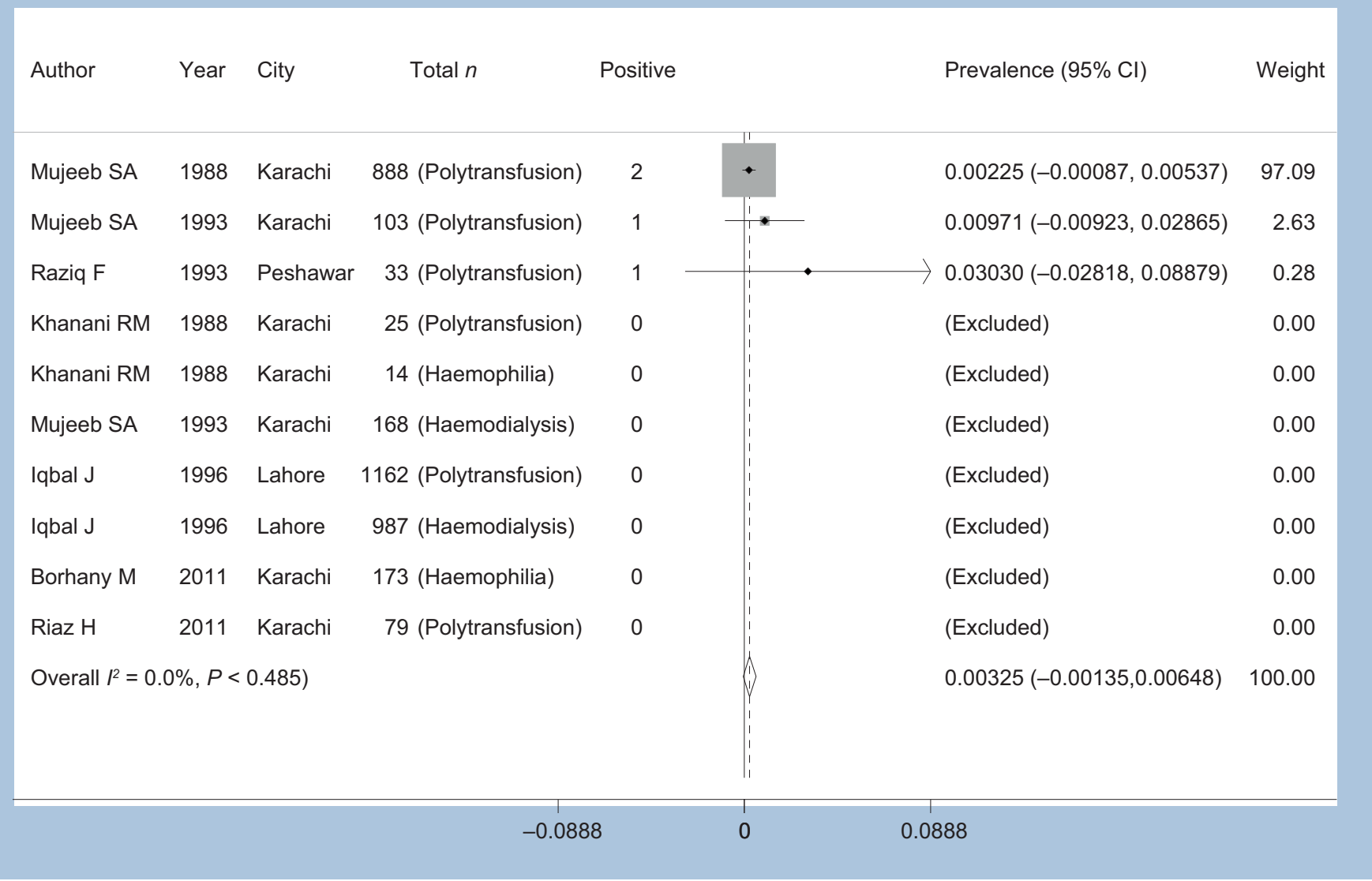

Figure 2: Prevalence of HIV positivity in blood recipients in Pakistan

Forest plot showing prevalence (\%) estimates (black solid diamonds) with $95 \%$ confidence intervals (bars). Shaded boxes denote the weight allocated to each study based on sample size. The pooled prevalence estimate is represented by the open diamond.

had non-availability of HIV kits for periods of 1-12 months. The same report documented the pooling of blood samples for HIV screening in four blood banks. The methodology was predominantly rapid qualitative assay, adopted by $44 / 63$ or $70 \%$ of blood banks, while ELISA was utilized in $15 / 63$ or $24 \%$ of blood banks. Four banks were not screening for HIV at all. It was also noted with concern that only two of the 63 surveyed blood banks had a standard operating procedure for HIV testing, while only one addressed the appropriate storage of the kits.

A recent survey report by Kassi et al. showed that $4(17 \%)$ of 23 blood banks were affiliated with either a government or semi-government institution; $916(70 \%)$ blood banks had a healthy donor recruitment programme and $2(9 \%)$ of the blood banks agreed that they recruited remunerated (paid) blood donors. Donors were screened for HIV in all 23 blood banks.

The authors' institutional blood bank data are comparable to published data from the country. However, the relatively greater seropositivity in voluntary donors and in females may be a consequence of the relatively small population denominator in these cohorts. The trend of HIV seropositivity seemed to be static over a period of years and the overall frequency still appears to be low.

\section{Current situation}

Owing to the current geopolitical situation, political turmoil and receding economy, Pakistan spends only $2 \%$ of its budget on health. Communicable diseases like hepatitis, malaria and tuberculosis are the top priorities for budget allocation. There is not only a lack of health insurance or medical coverage, but even hospital stays and medications are self-financed. Voluntary blood donations are sparse, and centralized blood banking is non-existent; hospitals are dependent on patients' attendance for their blood supply. Several items of blood-safety legislation were approved during 1997 to 2004 and a national blood policy and strategic framework was laid down in 20082014. However, these were never fully implemented. More recently, with the initiatives taken by NBTP in the country, there is hope that the blood-safety system will be reformed.

\section{Strengths and limitations of this study}

The study provides a comprehensive review of HIV seroprevalence in Pakistani blood donors in the past 25 years. It gives an insight into a very low risk of transfusiontransmitted HIV in the country at present. However, the studies are not representative and reflect only a small proportion of 
the blood that is used clinically in Pakistan. Moreover, nothing is known about the blood banks that are dependent on paid/ professional donors for their blood supply. Since females are underrepresented in blood donation, their HIV seroprevalence remains unknown. Similarly, there is no sustainability in the performance of public-sector blood banks, as the HIV kits may periodically be missing. The review was limited by the variation in the type of studies, patchy information, and lack of standardization in the methodologies. The number of blood recipients studied was too small to draw any conclusive result.

\section{Future directions}

With cooperation of the Government of Germany, regional blood centres are being established, while blood banks that already exist are reformed. ${ }^{2}$ Regional blood centres will be centrally monitored, with strict overall quality management and HIV surveillance. There is an urgent need to utilize the existing national HIV surveillance data to prevent the spread of HIV. ${ }^{51}$ HIV-reactive donors should be notified to a central authority and the tracking system should disallow subsequent donation. Motivation of non-remunerated blood donors is a key concept that underlies safe blood transfusion, ${ }^{52}$ and is one of the initiatives launched by WHO in 2004. The guidelines for blood transfusions developed by NBTP need to be implemented to avoid unnecessary transfusions. ${ }^{53}$ This would use evidencebased practice to drive the transfusion practices of Pakistan's physicians/surgeons. ${ }^{54}$ Serious gaps in knowledge about HIV have been identified in young people, ${ }^{55-57}$ including medical students. ${ }^{58}$ Nonetheless, media can be used as an effective tool for mass education about HIV/AIDS, ${ }^{59}$ and the medical personnel involved should insist on fully screened blood for their patients and avoid purchasing blood from unregistered blood banks.

\section{Conclusion}

At present, the published literature indicates a low risk of HIV transmission through transfusion of blood products in Pakistan. The data are minimal and patchy, with wide variation in methodologies that lack standardization. The low prevalence detected could also be highly significantly confounded by social and cultural factors. Thus, there is an urgent need for a national HIV surveillance system of blood donors and recipients, to elucidate the true magnitude of the HIV burden.

\section{REFERENCES}

1. Central Intelligence Agency. The world fact book. South Asia: Pakistan. (https://www.cia.gov/library/publications/the-world-factbook/geos/ pk.html, accessed 2 November 2015).

2. Zaheer HA, Waheed U. Legislative reforms of the blood transfusion system in Pakistan. Transfus Med. 2014;24(2):117-9. doi:10.1111/ tme.12107.

3. Salamat N. Challenges in the field of transfusion medicine in Pakistan. Hematology Updates Education Series. Pakistan Society of Hematology. 2009(1):110-25.

4. Luby S, Khanani R, Zia M, Vellani Z, Ali M, Qureshi AH, et al. Evaluation of blood bank practices in Karachi, Pakistan, and the government's response. Health Policy Plan. 2000;15(2):217-22.
5. Gilani I, Kayani ZA, Atique M. Knowledge, attitude and practices (kap) regarding blood donation prevalent in medical and paramedical personnel. J Coll Physicians Surg Pak. 2007;17(8):473-6.

6. Ahmad K. Pakistan investigates black market sale of HIV kits. Lancet. 2001;357(9264):1269.

7. Ali Shah S, Altaf A, Kristensen S. Missing HIV kits in Pakistan. Lancet. 2001;358(9285):923-4.

8. World Health Organization. Pakistan. HIV/AIDS (http://www.emro. who.int/pak/programmes/hiv-aids.html, accessed 2 November 2015).

9. Kassi M, Afghan AK, Khanani MR, Khan IA, Ali SH. Safe blood transfusion practices in blood banks of Karachi, Pakistan. Transfus Med. 2011;21(1):57-62. doi:10.1111/j.1365-3148.2010.01042.x.

10. Emmanuel F, Blanchard J, Zaheer HA, Reza T, Holte-McKenzie M. The HIV/AIDS Surveillance Project mapping approach: an innovative approach for mapping and size estimation for groups at a higher risk of HIV in Pakistan. AIDS. 24(Suppl. 2):S77-84. doi:10.1097/01. aids.0000386737.25296.c4.

11. Zaheer HA, Waheed U. Blood safety system reforms in Pakistan. Blood Transfus. 2014;12(4):452-7. doi:10.2450/2014.0253-13.

12. Ali SA, Donahue RM, Qureshi H, Vermund SH. Hepatitis B and hepatitis $\mathrm{C}$ in Pakistan: prevalence and risk factors. Int J Infect Dis. 2009;13(1):9-19. doi: 0.1016/j.ijid.2008.06.019.

13. Abdul Mujeeb, Hashmi MR. A study of HIV-antibody in sera of blood donors and people at risk. J Pak Med Assoc. 1988;38(8):221-2.

14. Khanani RM, Hafeez A, Rab SM, Rasheed S. Human immunodeficiency virus-associated disorders in Pakistan. AIDS Res Hum Retroviruses. 1988;4(2):149-54.

15. Stroup DF, Berlin JA, Morton SC, Olkin I, Williamson GD, Rennie D et al. Meta-analysis of observational studies in epidemiology: a proposal for reporting. JAMA. 2000;283(15):2008-12.

16. Wilson DB. Meta-analysis macros for SAS, SPSS, and Stata (http:// mason.gmu.edu/ dwilsonb/ma.html, accessed 2 November 2015).

17. Mujeeb SA, Khanani MR, Khursheed T, Siddiqui A. Prevalence of HIVinfection among blood donors. J Pak Med Assoc. 1991;41(10):253-4.

18. Kakepoto GN, Bhally HS, Khaliq G, Kayani N, Burney IA, Siddiqui $\mathrm{T}$ et al. Epidemiology of blood-borne viruses: a study of healthy blood donors in Southern Pakistan. Southeast Asian J Trop Med Public Health. 1996;27(4):703-6.

19. Mujeeb SA, Mehmood K. Prevalence of HBV, HCV, and HIV infections among family blood donors. Ann Saudi Med. 1996;16(6):702-3.

20. Abdul Mujeeb S, Aamir K, Mehmood K. Seroprevalence of HBV, HCV and HIV infections among college going first time voluntary blood donors. J Pak Med Assoc. 2000;50(8):269-70.

21. Ahmed F Shah SH, Tariq M, Khan JA. Prevalence of hepatitis B carrier and HIV in healthy blood donors at Ayub Teaching Hospital. Pakistan J Med Res. 2000;39(2):91-2.

22. Khan Z, Raziq F, Aslam N. Prevalence of HIV in blood donors in N.W.F.P. Journal Postgrad Med Inst (Peshawar - Pakistan). 2002;16(2):187-9 (http://www.pakmedinet.com/3719, accessed 16 November 2015).

23. Khattak MF, Salamat N, Bhatti FA, Qureshi TZ. Seroprevalence of hepatitis B, C and HIV in blood donors in northern Pakistan. J Pak Med Assoc. 2002;52(9):398-402.

24. Mumtaz S, Rehman M, Muzaffar M, Hassan M, Iqbal W. Frequency of seropositive blood donors for hepatitis $\mathrm{B}, \mathrm{C}$ and HIV viruses in railway hospital Rawalpindi. Pak J Med Res. 2002;41(2):51-3.

25. Rahman M, Akhtar GN, Lodhi Y. Transfusion transmitted HIV and HBV infections in Punjab, Pakistan. Pak J Med Sci. 2002;18(1):18-25.

26. Asif N, Khokhar N, Ilahi F. Sero-prevalence of HBV, HCV, and HIV infection among voluntary non remunerated and replacement donors in Northern Pakistan. Pak J Med Sci. 2004;20(1):24-8.

27. Mehmood MA, Khawar S, Anjum H, Ahmed SM, Rafiq S. Prevalence of hepatitis B, C and HIV infection in blood donors of Multan region. Ann King Edward Med Coll. 2004;10:(4):459-61.

28. Sheikh AA, Sheikh AS, Sheikh NS, Rafi-U-Shan, Malik MT, Afridi F. High frequency of false positive results in HIV screening in blood banks. J Ayub Med Coll Abbottabad. 2004;16:28-31. 


\section{Moiz et al.: HIV and blood transfusion in Pakistan}

29. Zaidi A, Tariq WZ, Haider KA, Ali L, Sattar A, Faqeer F et al. Seroprevalence of hepatitis B, C and HIV in healthy blood donors in northwest of Pakistan. Pak J Pathol. 2004;15(1):11-16.

30. Sirhindi GA, Khan AA, Alam SS, Ghori MA, Rehman R, Soomro NA et al. Frequency of hepatitis B, C and human immunodeficiency virus in blood donors at Shaikh Zayed hospital, Lahore. Proc Shaikh Zayed Postgrad Med Inst. 2005;19(1):33-6.

31. Khan MA, Rehman A, Ashraf M, Ali A, Ahraf M, Ditta A. Prevalence of HBV, HCV and HIV in blood donors at Liaquetpur. Profess Med J. 2006;13(1):23-6 (http://www.pakmedinet.com/9217, accessed 2 November 2015).

32. Fayyaz M, Qazi MA, Ahmed G, Khan MA, Chaudhary GMD. Hepatitis B, C \& HIV; sero-prevalence of infection in blood donors. Profess Med J. 2006;13(4):632-6.

33. Bhatti FA, Ullah Z, Salamat N, Ayub M, Ghani E. Anti-hepatits B core antigen testing, viral markers, and occult hepatitis $\mathrm{B}$ virus infection in Pakistani blood donors: implications for transfusion practice. Transfusion. 2007;47(1):74-9.

34. Khan ZT Asim S, Tariq Z, Ehsan IA, Malik RA, Ashfaq B et al. Prevalence of tranfusion transmitted infections in healthy blood donors in Rawalpindi district, Pakistan - a five year study. Int J Pathol. 2007;5(1):21-5.

35. Sultan F, Mehmood T, Mahmood MT. Infectious pathogens in volunteer and replacement blood donors in Pakistan: a ten-year experience. Int $\mathrm{J}$ Infect Dis. 2007;11(5):407-12.

36. Manzoor I, Hashmi N, Daud S, Ajmal S, Fatima H, Rasheed Z et al. Seroprevalence of transfusion transmissible infections (TTIS) in blood donors. Biomedica. 2009;25.

37. Shah SAR, Ehsan A. Seroprevalence of surrogate markers for hepatitis $\mathrm{B}$, hepatitis $\mathrm{C}$ and HIV in healthy blood donors at Shaikh Zayed Medical Complex, Lahore. Annals. 2009;15(1):5-10 (http://kemu.edu.pk/annals/ jan-mar-2009/Seroprevalence-of-Surrogate-Markers.pdf, accessed 2 November 2015).

38. Shaikh ZA. Analysis of blood donors at a major tertiary-care hospital of Karachi and seroprevalence of blood-borne hepatitis and HIV. Medical Channel. 2010;16(4):3.

39. Attaullah S, Khan S, Khan J. Trend of transfusion transmitted infections frequency in blood donors: provide a road map for its prevention and control. J Transl Med. 2012;10:20. doi:10.1186/1479-5876-10-20.

40. Kayani N, Sheikh A, Khan A, Mithani C, Khurshid M. A view of HIV-I infection in Karachi. J Pak Med Assoc. 1994;44(1):8-11.

41. Khan A BS, Alvi MI and Qazi A. Seroprevalence of hepatitis B, hepatitis $\mathrm{C}$ and HIV in blood donors of Peshawar. Gomal Journal of Medical Sciences. 2011;9(1):46-50.

42. Mujeeb SA, Hafeez A. Prevalence and pattern of HIV infection in Karachi. J Pak Med Assoc. 1993;43(1):2-4.

43. Raziq F. Serosurveillance of HIV infection. Pak J Pathol. 1993;4(2):11719.

44. Iqbal J, Rehan N. Sero-prevalence of HIV: six years' experience at Shaikh Zayed Hospital, Lahore. J Pak Med Assoc. 1996;46(11):255-8.

45. Borhany M, Shamsi T, Boota S, Ali H, Tahir N, Naz A et al. Transfusion transmitted infections in patients with hemophilia of Karachi, Pakistan. Clin Appl Thromb Hemost. 2011;17(6):651-5. doi: $10.1177 / 1076029611398122$.
46. Riaz H, Riaz T, Ullah F, Aziz S, Khan MU, Pervaiz R et al. Assessment of the seroprevalence of viral hepatitis B, viral hepatitis C and HIV in multitransfused thalassaemia major patients in Karachi, Pakistan. Trop Doct. 2011;41(1):23-5. doi:10.1258/td.2010.100158.

47. Makroo RN, Chowdhry M, Bhatia A, Arora B, Rosamma NL. Prevalence of HIV among blood donors in a tertiary care centre of North India. Indian J Med Res. 2011;134(6):950-3. doi:10.4103/0971-5916.92640.

48. Cheraghali A. Overview of blood transfusion system of Iran: 20022011. Iran J Public Health. 2012;41(8):89-93.

49. Shrestha AC, Ghimire P, Tiwari BR, Rajkarnikar M. Transfusiontransmissible infections among blood donors in Kathmandu, Nepal. J Infect Dev Ctries. 2009;3(10):794-7.

50. Khan AA, Khan A. The HIV epidemic in Pakistan. J Pak Med Assoc. 60(4):300-307.

51. Emmanuel F, Adrien A, Athar U, Imran M, Reza T, Blanchard J. Using surveillance data for action: lessons learnt from the second generation HIV/AIDS surveillance project in Pakistan. East Mediterr Health J. 17(8):712-8.

52. Leikola J. Non-remunerated donations. Dev Biol Stand. 1993;81:51-6.

53. Kazi BM. Standards and guidelines for blood transfsuion services. Islamabad, Pakistan:World Health Organization/National institute of Health/Federal Health Ministry, Government of Pakistan; 1999 (http://www.nacp.gov.pk/policies_and_guidelines/blood transfusion/Standards\%20and\%20Guidelines $\% 20$ For $\% 20$ Blood $\% 2 \overline{0}$ Transfusion\%20Services.pdf, accessed 2 November 2015).

54. Kashif M, Adil SN. Judicious use of blood. J Pak Med Assoc. 2011;60(5):332-3 (http://www.jpma.org.pk/full_article_text. php?article_id=2036, accessed 2 November 2015).

55. Haider G, Zohra N, Nisar N, Munir AA. Knowledge about AIDS/HIV infection among women attending obstetrics and gynaecology clinic at a university hospital. J Pak Med Assoc. 2009;59(2):95-8.

56. Yousuf F, Haider G, Muhammad N, Haider A. Awareness of women towards an emerging threat. J Ayub Med Coll Abbottabad. 2009;21(1):79-82.

57. Farid-ul-Hasnain S, Johansson E, Krantz G. What do young adults know about the HIV/AIDS epidemic? Findings from a population based study in Karachi, Pakistan. BMC Infect Dis. 2009;9:38. doi:10.1186/14712334-9-38.

58. Anjum Q, Siddiqui H, Ahmed Y, Rizvi SR, Usman Y. Knowledge of students regarding hepatitis and HIV/AIDS of a private medical university in Karachi. J Pak Med Assoc. 2005;55(7):285-8.

59. Lynn W. Pakistan launches media blitz on AIDS. Glob AIDS news. 1994(2): 1-2.

How to cite this article: Moiz $\mathrm{B}$, Ali $\mathrm{B}$, Chatha $\mathrm{MH}$, Raheem A, Zaheer HA. HIV prevelance in blood donors and recipients in Pakistan: a meta-analysis and analysis of blood-bank data. WHO South-East Asia J Public Health 2015; 4(2): 176-183.

Source of Support: Nil. Conflict of Interest: None declared. Contributorship: BM conceived the idea, analysed data and wrote the manuscript; BA collected data, did the literature search and wrote part of the manuscript; MHC collected data; AR analysed the data and computed the statistics; and HAZ critically analysed the paper. 